Article

\title{
Dihydroberkleasmin A: A New Eremophilane Sesquiterpenoid from the Fermentation Broth of the Plant Endophytic Fungus Pestalotiopsis photiniae
}

\author{
Xiao-Long Yang ${ }^{1,2, *}$, Su Zhang ${ }^{2}$, Hua-Jie Zhu ${ }^{1}$ and Du-Qiang Luo ${ }^{1,3, *}$
}

1 Key Laboratory of Pharmaceutical Chemistry and Molecular Diagnosis of Ministry of Education, Hebei University, Baoding 071002, China

2 College of Pharmaceutical Science, Hebei University, Baoding 071002, China

3 College of Life Science, Hebei University, Baoding 071002, China

* Authors to whom correspondence should be addressed; E-Mail: duqiangluo@163.com (D.-Q.L.); yx119830915@163.com (X.-L.Y.).

Received: 11 January 2011; in revised form: 15 January 2011 / Accepted: 19 January 2011 /

Published: 23 February 2011

\begin{abstract}
Dihydroberkleasmin A (1), a new ester-substituted sesquiterpenoid related to the eremophilane class, together with the known compound berkleasmin C (2), were isolated from the fermentation broth of the plant endophytic fungus Pestalotiopsis photiniae. The structure of dihydroberkleasmin A (1) was elucidated by extensive spectroscopic analysis. The stereochemistry was assigned by comparison of the NMR spectroscopic data with those of berkleasmin A.
\end{abstract}

Keywords: Pestalotiopsis photiniae; eremophilane sesquiterpenoid; dihydroberkleasmin A

\section{Introduction}

Fungi of the genus Pestalotiopsis (Amphisphaeriaceae), as one class of the most widely distributed endophytic fungi, are common in their distribution, and many are saprobes, while others are either pathogenic or endophytic to living plants [1-4]. Since discovery of the anticancer agent taxol from an endophytic fungal strain of the genus Pestalotiopsis [5,6], interest in searching for bioactive compounds from this fungal genus has increased considerably. Up to date, about 300 species of the genus Pestalotiopsis have been recorded in China, but only about $10 \%$ of these species referred to 
chemical investigations. Previous chemical studies of some species of this genus have afforded a variety of bioactive metabolites [7-18]. In the course of our research on bioactive metabolites of the genus Pestalotiopsis in China, the present study was undertaken to investigate the chemical constituents of the culture broth of Pestalotiopsis photiniae isolated from the branch of Podocarpus macrophyllus in Hainan (People's Republic of China), and have led to the isolation of a new eremophilane sesquiterpenoid named dihydroberkleasmin A (1) and one known compound, berkleasmin C (2). Details of the isolation and structural elucidation of $\mathbf{1}$ are reported herein.

Figure 1. The structures of compounds 1, 2 and berkleasmin A.

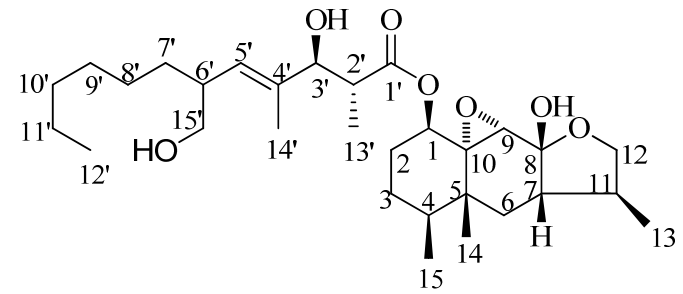

1

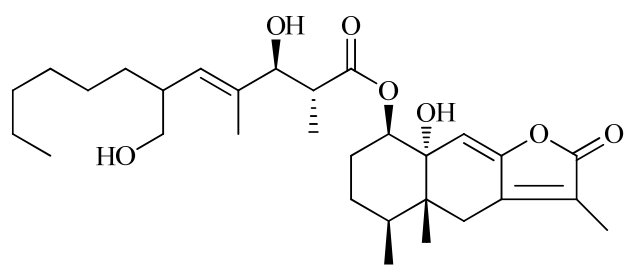

2

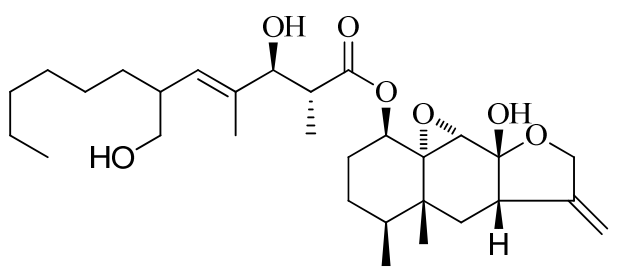

berkleasmin A

\section{Results and Discussion}

Compound 1 was obtained as an optically active white powder, $[\alpha]_{\mathrm{D}}^{22.0}=+70^{\circ}(\mathrm{c}=0.1, \mathrm{MeOH})$ that gave a quasi-molecular ion peak at $[\mathrm{M}+\mathrm{Na}]^{+} \mathrm{m} / \mathrm{z} 545.3458$ in the HR-ESI-MS (positive mode), consistent with a molecular formula of $\mathrm{C}_{30} \mathrm{H}_{50} \mathrm{O}_{7}$ (calcd. for $\mathrm{C}_{30} \mathrm{H}_{50} \mathrm{O}_{7} \mathrm{Na}$, 545.3454), requiring six degrees of unsaturation. The IR spectrum revealed absorption bands of double bond $\left(1,604 \mathrm{~cm}^{-1}\right)$, hydroxyl $\left(3,424 \mathrm{~cm}^{-1}\right)$ and carbonyl $\left(1,736 \mathrm{~cm}^{-1}\right)$ groups. There were 30 signals observed in the ${ }^{13} \mathrm{C}$ NMR spectrum (Table 1). Analysis of the ${ }^{13} \mathrm{C}-\mathrm{NMR}$, DEPT, and HSQC spectra revealed that $\mathbf{1}$ contained one carbonyl carbon, seven oxygenated carbons, two olefinic carbons, eight methylene carbons, five methine carbons, one quaternary carbon, and six methyl carbons. Analysis of the ${ }^{1} \mathrm{H}-$ NMR spectrum (Table 1) indicated the presence of six methyl signals including one tertiary methyl $\left[\delta_{H}\right.$ $1.62(\mathrm{~s}), 1.15$ (s), 1.13 (d, $J=7.2 \mathrm{~Hz}), 1.05$ (d, $J=6.6 \mathrm{~Hz}), 0.89$ (d, $J=6.7 \mathrm{~Hz}), 0.87$ (t, $J=7.2 \mathrm{~Hz}$ )], one olefinic proton signal $\left[\delta_{H} 5.23(\mathrm{~d}, J=10.1 \mathrm{~Hz})\right]$, two oxygenated methylene protons signals $\left[\delta_{H}\right.$ $3.95,3.54(\mathrm{~m}), 3.63,3.34(\mathrm{~m})]$ and three oxygenated methine proton signals $\left[\delta_{H} 4.50(\mathrm{~m}), 4.09(\mathrm{~d}\right.$, $J=7.4 \mathrm{~Hz}$ ), 3.27 (s)]. By careful analysis of NMR data, we found that the spectral data of 1 were similar to those of berkleasmin A recently reported from the saprobic fungus Berkleasmium nigroapicale [19], and this suggested that $\mathbf{1}$ has a tricyclic sesquiterpene core attached to a long-chain acid through an ester linkage. The distinct differences between 1 and berkleasmin $\mathrm{A}$ are: the chemical shifts value at C-11 and C-13 of $1\left[\delta_{C} 42.7(\mathrm{~d}, \mathrm{C}-11), 16.0\right.$ (q, C-13)] are absent in berkleasmin $\mathrm{A}\left[\delta_{C}\right.$ 
$151.2(\mathrm{~s}, \mathrm{C}-11), 104.3(\mathrm{t}, \mathrm{C}-13)]$. In addition, the chemical shifts value at C-7 $\left(\delta_{C} 48.3\right)$ and $\mathrm{C}-12\left(\delta_{C}\right.$ $72.3)$ in 1 were shifted downfield compared to berkleasmin A [ $\delta_{C} 44.6$ (s, C-7), 69.9 (t, C-12)] because of replacement of the exomethylene group in berkleasmin A by a methyl group in compound $\mathbf{1}$.

Table 1. ${ }^{1} \mathrm{H}-(600 \mathrm{MHz})$ and ${ }^{13} \mathrm{C}-\mathrm{NMR}(150 \mathrm{MHz})$ data for $\mathbf{1}$ in $\mathrm{CDCl}_{3}$, and the literature data for berkleasmin A [19].

\begin{tabular}{clrrrr}
\hline No. & \multicolumn{1}{c}{$\boldsymbol{\delta}_{\boldsymbol{H}}$} & \multicolumn{1}{c}{$\boldsymbol{\delta}_{\boldsymbol{C}}$} & No. & \multicolumn{1}{c}{$\boldsymbol{\delta}_{\boldsymbol{H}}$} & \multicolumn{1}{c}{$\boldsymbol{\delta}_{\boldsymbol{C}}$} \\
\hline 1 & $4.50(\mathrm{~m})$ & $74.8(\mathrm{~d})$ & $1^{\prime}$ & & $175.3(\mathrm{~s})$ \\
2 & $1.86,1.77(\mathrm{~m})$ & $28.5(\mathrm{t})$ & $2^{\prime}$ & $2.71(\mathrm{dq}, 7.3,7.4)$ & $42.6(\mathrm{~d})$ \\
3 & $1.44,1.76(\mathrm{~m})$ & $25.7(\mathrm{t})$ & $3^{\prime}$ & $4.09(\mathrm{~d}, 7.4)$ & $79.1(\mathrm{~d})$ \\
4 & $1.58(\mathrm{~m})$ & $38.9(\mathrm{~d})$ & $4^{\prime}$ & & $137.5(\mathrm{~s})$ \\
5 & & $36.2(\mathrm{~s})$ & $5^{\prime}$ & $5.23(\mathrm{~d}, 10.1)$ & $130.8(\mathrm{~d})$ \\
6 & $\alpha 1.30(\mathrm{t}, 13.0)$ & $37.2(\mathrm{t})$ & $6^{\prime}$ & $2.56(\mathrm{~m})$ & $40.8(\mathrm{~d})$ \\
& $\beta 1.64(\mathrm{dd}, 13.0,6.8)$ & & & & \\
7 & $1.70(\mathrm{~m})$ & $48.3(\mathrm{~d})$ & $7^{\prime}$ & $1.09,1.29(\mathrm{~m})$ & $31.3(\mathrm{t})$ \\
8 & & $102.3(\mathrm{~s})$ & $8^{\prime}$ & $1.21-1.28(\mathrm{~m})$ & $27.2(\mathrm{t})$ \\
9 & $3.27(\mathrm{~s})$ & $62.4(\mathrm{~d})$ & $9^{\prime}$ & $1.21-1.28(\mathrm{~m})$ & $29.4(\mathrm{t})$ \\
10 & & $62.8(\mathrm{~s})$ & $10^{\prime}$ & $1.21-1.28(\mathrm{~m})$ & $31.8(\mathrm{t})$ \\
11 & $1.80(\mathrm{~m})$ & $42.7(\mathrm{~d})$ & $11^{\prime}$ & $1.21-1.28(\mathrm{~m})$ & $22.6(\mathrm{t})$ \\
12 & $3.54,3.95(\mathrm{~m})$ & $72.3(\mathrm{t})$ & $12^{\prime}$ & $0.87(\mathrm{t}, 7.2)$ & $14.1(\mathrm{q})$ \\
13 & $1.05(\mathrm{~d}, 6.6)$ & $16.0(\mathrm{q})$ & $13^{\prime}$ & $1.13(\mathrm{~d}, 7.2)$ & $15.0(\mathrm{q})$ \\
14 & $1.15(\mathrm{~s})$ & $15.3(\mathrm{q})$ & $14^{\prime}$ & $1.62(\mathrm{~s})$ & $12.2(\mathrm{q})$ \\
15 & $0.89(\mathrm{~d}, 6.7)$ & $15.1(\mathrm{q})$ & $15^{\prime}$ & $3.34,3.63(\mathrm{~m})$ & $66.5(\mathrm{t})$ \\
\hline
\end{tabular}

Further interpretation of the HMBC spectrum showed the following long-range correlations (Figure

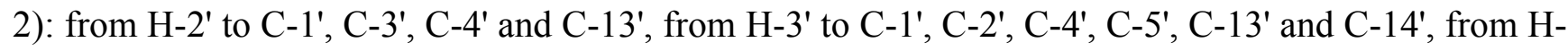
5' to C-3', C-14' and C-15', from H-6' to C-4', C-5', C-7' and C-15', from $\mathrm{H}_{3}-13^{\prime}$ to $\mathrm{C}-1$ ', C-2' and C-3', from $\mathrm{H}-14$ ' to $\mathrm{C}-3^{\prime}, \mathrm{C}-4^{\prime}$ and $\mathrm{C}-5^{\prime}$, from $\mathrm{H}-15^{\prime}$ to $\mathrm{C}-5$ ' and $\mathrm{C}-\mathrm{7}^{\prime}$.

Figure 2. The fragments and selected HMBC correlations of $\mathbf{1 .}$

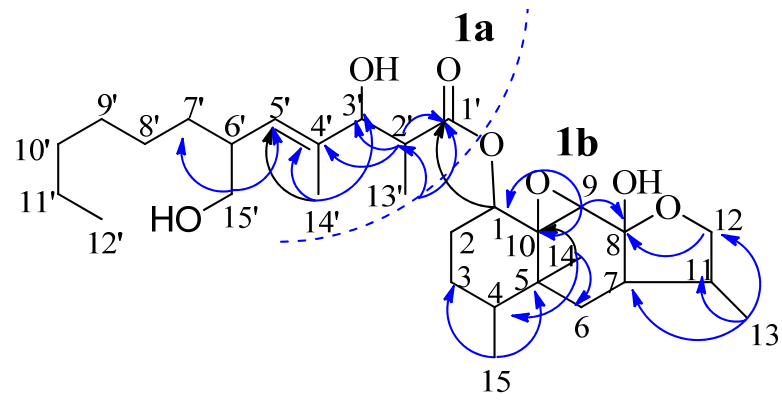

The above spectral evidence, along with the proton spin system: $\mathrm{H}-3^{\prime} / \mathrm{H}-2^{\prime}$ and $\mathrm{H}-2^{\prime} / \mathrm{H}_{3}-13^{\prime} ; \mathrm{H}-5^{\prime} / \mathrm{H}-$ $6^{\prime} / \mathrm{H}-7^{\prime} / \mathrm{H}-8^{\prime} / \mathrm{H}-9^{\prime} / \mathrm{H}-10^{\prime} / \mathrm{H}-11^{\prime} / \mathrm{H}_{3}-12^{\prime}$ and $\mathrm{H}-6^{\prime} / \mathrm{H}-15^{\prime}$ deduced from ${ }^{1} \mathrm{H},{ }^{1} \mathrm{H}-\mathrm{COSY}$ (Figure 3) correlations, led to the establishment of the partial structure 1a (Figure 2). In addition, HMBC spectrum also showed the long-range couplings from $\mathrm{H}-1$ to $\mathrm{C}-1$ ', $\mathrm{C}-3$ and $\mathrm{C}-10$, from $\mathrm{H}-7$ to $\mathrm{C}-6, \mathrm{C}-8$, C-9 and C-11, from H-9 to C-1, C-7, C-8 and C-10, from H-11 to C-6, C-7 and C-12, from H-12 to C- 
7, C-8, C-11 and C-13, from $\mathrm{H}_{3}-13$ to $\mathrm{C}-7, \mathrm{C}-11$ and $\mathrm{C}-12$, from $\mathrm{H}_{3}-14$ to $\mathrm{C}-4, \mathrm{C}-5, \mathrm{C}-6$ and C-10, from $\mathrm{H}_{3}-15$ to $\mathrm{C}-3, \mathrm{C}-4$ and $\mathrm{C}-5$. These spectral data, coupling with the following correlations: $\mathrm{H}-1 / \mathrm{H}-$ 2/H-3/H-4/H $-15 ; \mathrm{H}-12 / \mathrm{H}-11 / \mathrm{H}-7 / \mathrm{H}-6$ and $\mathrm{H}-11 / \mathrm{H}_{3}-13$ established by ${ }^{1} \mathrm{H},{ }^{1} \mathrm{H}-\mathrm{COSY}$ correlations (Figure 3), gave rise to another partial structure 1b (Figure 2). The ester bond linkage, C-1'-O-C-1, between fragments 1a and 1b was clearly determined by the HMBC correlation of $\mathrm{H}-1$ with C-1', which permitted the construction of the planar structure of $\mathbf{1}$ as shown in Figure 2.

Figure 3. The ${ }^{1} \mathrm{H},{ }^{1} \mathrm{H}-\mathrm{COSY}$ and key selected NOESY correlations of $\mathbf{1}$.
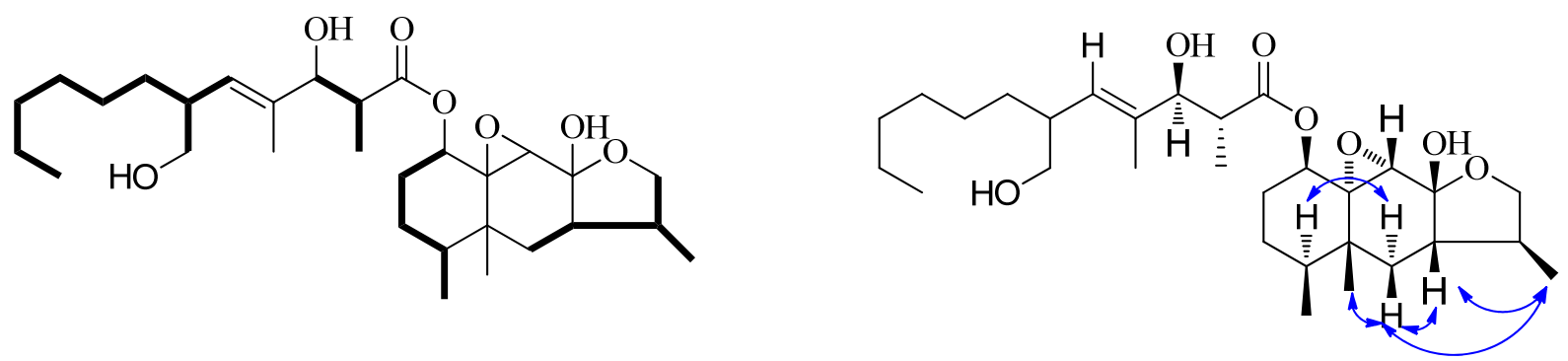

The relative configuration of $\mathbf{1}$ was elucidated by analysis of the partial NOESY data and comparison chemical shifts with berkleasmins A-E and cryptosphaerolide [19,20]. The same relative stereochemistry of C-1, C-4, C-5, C-8, C-9, C-10, C-2', C-3' and C-4' in 1 as in berkleasmins A-E were deduced from the very similar carbon and proton chemical shifts. The $\beta$-oriented configuration of $\mathrm{H}-7$ and $\mathrm{H}_{3}-15$ was indicated by the observation of NOE interactions (Figure 3 ) between $\mathrm{H}-6 \beta\left(\delta_{H} 1.64\right.$ (dd, $13.0,6.8)$ ) and $\mathrm{H}-7$, and $\mathrm{H}-6 \alpha$ and $\mathrm{H}-4$, respectively. The relative configuration of $\mathrm{H}_{3}-13$ and $\mathrm{H}_{3}-14$ should both also be $\beta$-oriented deduced from the observation of NOE interactions between $\mathrm{H}-7$ and $\mathrm{H}_{3}-$ 13 , and $\mathrm{H}-6 \beta$ and $\mathrm{H}_{3}-14$, respectively. The $E$-configuration of trisubstituted olefin was assigned by NOESY correlations from H-3' to H-5', and from H-6' to H-14'. Because of some significant signal overlap, we tried to crystallize of $\mathbf{1}$ in different solvents but finally failed to obtain crystals. Due to small quantity sample, we can not further determine the relative configuration of $\mathbf{1}$ by chemical methods. Finally, the relative configuration of remaining chiral centers of 1 except for C-6' were determined by comparison chemical shifts with berkleasmins A-E. Unfortunately, the relative configuration of C-6' remains unsigned through only spectroscopic analysis. Through comparison the NMR data of 1 with that of berkleasmin A, the absolute configurations of C-1, C-8, C-2', and C-3' in 1 as berkleasmin A were determined to be $1 R, 8 S, 2^{\prime} R, 3^{\prime} S$.

Comparison of the physicochemical properties and optical rotation data $\left([\alpha]_{\mathrm{D}}{ }^{26}=+10^{\circ}(\mathrm{c}=0.1\right.$, $\left.\mathrm{CHCl}_{3}\right)$ ) with reported data allowed identifying the compound 2 as berkleasmin $\mathrm{C}$ [19], recently reported from the saprobic fungus Berkleasmium nigroapicale and shown to possess cytotoxicity against anti-cancer cell-lines (NCI-H187, MCF-7, and KB) and antimalarial activities. The relative and absolute configurations of 2 were from literature [19].

\section{Experimental}

\subsection{General}

Optical rotations: Perkin-Elmer 341 spectropolarimeter. IR spectra: Perkin-Elmer 577 spectrometer; $\mathrm{KBr}$ pellets; in $\mathrm{cm}^{-1}$. NMR spectra: Bruker AM-600 spectrometer; $\delta$ in ppm, $J$ in $\mathrm{Hz} ; \mathrm{Me}_{4} \mathrm{Si}$ as internal 
standard, measured in $\mathrm{CDCl}_{3}$. FT-MS spectra: Bruker Apex-Ultra 7.0 T spectrometer, in $\mathrm{m} / z$. Column chromatography (CC): silica gel (200 300 mesh, Yantai Zhi Fu chemical Co., Ltd., People's Republic of China), RP-18 (12 nm, S-50 um, YMC Co., Ltd., Japan), TLC: silica gel GF 254 plates (Yantai Zhi $\mathrm{Fu}$ chemical Co., Ltd, People's Republic of China) and Sephadex LH-20 gel (25 100 $\mu \mathrm{m}$, GE Healthcare Co., Ltd., Sweden).

\subsection{Fungal Material and Cultivation Conditions}

Pestalotiopsis photiniae was isolated from the branches of Podocarpus macrophyllus in Hainan, People's Republic of China, in April, 2008, and identified by Professor Jing-Ze Zhang, Institute of Biotechnology, Zhejiang University. The isolate was assigned the accession number L328 in the culture collection at College of Life Science, Key Laboratory of Medicinal Chemistry and Molecular Diagnosis of Ministry of Education, Hebei University. The fungal strain was cultured on slants of potato dextrose agar (CPDA ) at $28{ }^{\circ} \mathrm{C}$ for 7 days, and then inoculated into a $500 \mathrm{~mL}$ Erlenmeyer flask containing $100 \mathrm{~mL}$ of medium (glucose $20 \mathrm{~g}$, potato (peeled) $200 \mathrm{~g}, \mathrm{KH}_{2} \mathrm{PO}_{4} 3 \mathrm{~g}, \mathrm{MgSO}_{4} 1.5 \mathrm{~g}$, citric acid $0.1 \mathrm{~g}$, and thiamin hydrochloride $10 \mathrm{mg}$ in 1.0 liter deionized $\mathrm{H}_{2} \mathrm{O}$ ). The final $\mathrm{pH}$ of the media was adjusted to 6.5 before sterilization. After 7 days of incubation at $28{ }^{\circ} \mathrm{C}$ on rotary shakers at $150 \mathrm{rpm}$, $25 \mathrm{~mL}$ of culture liquid were transferred as seed into each 1,000 mL Erlenmeyer flask containing $250 \mathrm{~mL}$ of medium and static fermentation was carried out on a rotary shaker for 30 days.

\subsection{Extraction and Isolation}

The culture broth $(20 \mathrm{~L})$ was extracted three times with ethyl acetate. Evaporation of the solvent in vacuo gave a brown oily residue (18.0 g), which was subjected to column chromatography (silica gel), eluted with petroleum ether/acetone [100:0, 98:2, 95:5, 90:10, 80:20, 50:50 (v/v)] to afford six fractions Fr. 1-6. Fr. 5 (3.0 g) eluted with petroleum ether/acetone (80:20) was further purified by CC (silica gel; $\mathrm{CHCl}_{3}$ /acetone, 8:1) to afford eight fractions Fr. 5.1-5.8. Fr. 5.3 (500 mg) was subjected to Sephadex LH-20 chromatography $\left(\mathrm{CHCl}_{3} / \mathrm{MeOH}, 1: 1\right)$ to afford compounds 1 (3.0 mg) and 2 (2.5 mg).

Dihydroberkleasmin A (1): Isolated as white powder, $[\alpha]_{\mathrm{D}}{ }^{22}=+70^{\circ}(\mathrm{c}=0.1, \mathrm{MeOH})$. IR $(\mathrm{KBr}) \mathrm{v}_{\max }$ : 3,424 $(\mathrm{OH}), 1,736(\mathrm{C}=\mathrm{O}), 1,604(\mathrm{C}=\mathrm{C}) \mathrm{cm}^{-1} \cdot{ }^{13} \mathrm{C}-\left(150 \mathrm{MHz}, \mathrm{CDCl}_{3}\right)$ and ${ }^{1} \mathrm{H}-\mathrm{NMR}(600 \mathrm{MHz}$, $\mathrm{CDCl}_{3}$ ): see Table 1. Positive ion ESI-MS $m / z(\%): 545[\mathrm{M}+\mathrm{Na}]^{+}(21), 1,068[2 \mathrm{M}+\mathrm{Na}+\mathrm{H}]^{+}(7)$. Positive ion HR-ESI-MS [M+Na] $]^{+} m / z 545.3458$ (calcd for $\mathrm{C}_{30} \mathrm{H}_{50} \mathrm{O}_{7} \mathrm{Na}, 545.3454$ ).

\section{Conclusions}

In summary, we have isolated a new eremophilane-type sesquiterpene, named dihydroberkleasmin A (1), together with one known compound, berkleasmin C (2), from the culture broth of Pestalotiopsis photiniae. Eremophilane-type sesquiterpenes, including those with similar skeletons such as berkleasmins A-C, exist widely as constituents of various plants, while there have been several reports as fungal secondary metabolites mostly from family Xylariaceae. There has been no reported about eremophilane-type sesquiterpenes from the genus Pestalotiopsis. 


\section{Acknowledgements}

This work was supported by the programs for New Century Excellent Talents in University (NCET09-0112), the Key Project of Chinese Ministry of Education and the Key Applied Basic Research Programs of Hebei Province (0996030917D) and National Natural Science Foundation of China (31071701).

\section{References}

1. Suryanarayanan, T.S.; Senthilarasu, G.; Muruganandam, V. Endophytic fungi from Cuscuta reflexa and its host plants. Fungal Divers. 2000, 4, 117-123.

2. Toofanee, S.B.; Dulymamode, R. Fungal endophytes associated with Cordemoya integrifolia. Fungal Divers. 2002, 11, 169-175.

3. Cannon, P.F.; Simmons, C.M. Diversity and host preference of leaf endophytic fungi in the Iwokrama Forest Reserve, Guyana. Mycologia 2002, 94, 210-220.

4. Jeewon, R.; Liew, E.C.Y.; Simpson, J.A.; Hodgkiss, I.J.; Hyde, K.D. Phylogenetic significance of morphological characters in the taxonomy of Pestalotiopsis species. Mol. Phylogenet. Evol. 2003, 27, 372-383.

5. Strobel, G.A.; Hess, W.M.; Ford, E.; Sidhu, R.S.; Yang, X. Endophytic fungi in grasses and woody plants. J. Ind. Microbiol. 1996, 17, 417-423.

6. Li, J.Y.; Strobel, G.A.; Hess, W.M.; Ford, E. Endophytic taxol-producing fungi from bald cypress. Taxodium distichum. Microbiology 1996, 142, 2223-2226.

7. Liu, L.; Liu, S.C.; Chen, X.L.; Guo, L.D.; Che, Y.S. Pestalofones A-E, bioactive cyclohexanone derivatives from the plant endophytic fungus Pestalotiopsis fici. Bioorg. Med. Chem. 2009, 17, 606-613.

8. Ding, G.; Li, Y.; Fu, S.B.; Liu, S.C.; Wei, J.C.; Che, Y.S. Ambuic acid and torreyanic acid derivatives from the endolichenic fungus Pestalotiopsis sp. J. Nat. Prod. 2009, 72, 182-185.

9. Xu, J.; Kjer, J.L.; Sendker, J.; Wray, V.; Guan, H.S.; Edrada, R.; Lin, W.; Wu, J.; Proksch, P. Chromones from the endophytic fungus Pestalotiopsis sp. isolated from the Chinese mangrove plant Rhizophora mucronata. J. Nat. Prod. 2009, 72, 662-665.

10. Ding, G.; Zheng, Z.H.; Liu, S.C.; Zhang, H.; Guo, L.D.; Che, Y.S. Photinides A-F, cytotoxic benzofuranone-derived $\gamma$-Lactones from the plant endophytic fungus Pestalotiopsis photiniae. J. Nat. Prod. 2009, 72, 942-945.

11. Liu, L.; Li, Y.; Liu, S.C.; Zheng, Z.H.; Chen, X.L.; Zhang, H.; Guo, L.D.; Che, Y.S. Chloropestolide A, an antitumor metabolite with an unprecedented spiroketal skeleton from Pestalotiopsis fici. Org. Lett. 2009, 11, 2836-2839.

12. Liu, L.; Liu, S.C.; Niu, S.B.; Guo, L.D.; Chen, X.L.; Che, Y.S. Isoprenylated chromone derivatives from the plant endophytic fungus Pestalotiopsis fici. J. Nat. Prod. 2009, 72, 1482-1486.

13. Ding, G.; Jiang, L.H.; Guo, L.D.; Chen, X.L.; Zhang, H.; Che, Y.C. Pestalazines and pestalamides, bioactive metabolites from the plant pathogenic fungus Pestalotiopsis theae. J. Nat. Prod. 2008, 71, 1861-1865. 
14. Li, E.; Jiang, L.H.; Guo, L.D.; Zhang, H.; Che, Y.S. Pestalachlorides A-C, antifungal metabolites from the plant endophytic fungus Pestalotiopsis adusta. Bioorg. Med. Chem. 2008, 16, 7894-7899.

15. Zhang, Y.L.; Ge. H.M.; Li, F.; Song, Y.C.; Tan, R.X. New phytotoxic metabolites from Pestalotiopsis sp. HC02, a fungus residing in chondracris rosee gut. Chem. Biodivers. 2008, 5, 2402-2407.

16. Ding, G.; Liu, S.C.; Guo, L.D.; Zhou, Y.G.; Che, Y.S. Antifungal metabolites from the plant endophytic fungus Pestalotiopsis foedan. J. Nat. Prod. 2008, 72, 615-618.

17. Li, E.; Tian, R.R.; Liu, S.C.; Chen, X.L.; Guo, L.D.; Che, Y.S. Pestalotheols A-D, bioactive metabolites from the plant endophytic fungus Pestalotiopsis theae. J. Nat. Prod. 2008, 71, 664-668.

18. Liu, L.; Liu, S.C.; Jiang, L.H.; Chen, X.L.; Guo, L.D.; Che, Y.S. Chloropupukeananin, the first chlorinated pupukeanane derivative, and its precursors from Pestalotiopsis fici. Org. Lett. 2008, 10, 1397-1400.

19. Isaka, M.; Srisanoh, U.; Veeranondha, S.; Choowong, W.; Lumyong, S. Cytotoxic eremophilane sesquiterpenoids from the saprobic fungus Berkleasmium nigroapicale BCC 8220. Tetrahedron 2009, 65, 8808-8815.

20. Oh, H.; Jensen, P.R.; Murphy, B.T.; Fiorilla, C.; Sullivan, J.F.; Ramsey, T.; Fenical, W. Cryptosphaerolide, a cytotoxic mcl-1 inhibitor from a marine-derived ascomycete related to the genus Cryptosphaeria. J. Nat. Prod. 2010, 73, 998-1001.

Sample Availability: Samples of compounds 1-2 are available from the authors.

(C) 2011 by the authors; licensee MDPI, Basel, Switzerland. This article is an open access article distributed under the terms and conditions of the Creative Commons Attribution license (http://creativecommons.org/licenses/by/3.0/). 